\title{
1 Identification of Host Biomarkers of EBV Latency IIb and Latency III
}

2 Running Title: Host biomarkers of EBV latency IIb and latency III

3 Joshua E. Messinger ${ }^{1}$, Joanne Dai ${ }^{1}$, Lyla J. Stanland ${ }^{1}$, Alexander M. Price ${ }^{1 *}$ \& Micah A. 4 Luftig $^{1 \#}$

$5 \quad{ }^{1}$ Department of Molecular Genetics and Microbiology, Duke Center for Virology, Duke

6 University School of Medicine Durham, NC, USA

7

8

$9{ }^{*}$ Current Address: Division of Protective Immunity and Division of Cancer Pathobiology,

10 Children's Hospital of Philadelphia, Philadelphia, PA, USA

11 \#Corresponding author: Micah A. Luftig

12 Micah.luftig@duke.edu

13 Phone: 919-668-3091 


\section{ABSTRACT}

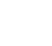

Deciphering the molecular pathogenesis of virally induced cancers is challenging due, in part, to the heterogeneity of both viral and host gene expression. Epstein-Barr Virus (EBV) is a ubiquitous herpesvirus prevalent in B-cell lymphomas of the immune suppressed. EBV infection of primary human B cells leads to their immortalization into lymphoblastoid cell lines (LCLs) serving as a model of these lymphomas. In previous studies, our lab has described a temporal model for immortalization with an initial phase characterized by expression of the Epstein-Barr Nuclear Antigens (EBNAs), high c-Myc activity, and hyper-proliferation in the absence of the Latent Membrane Proteins (LMPs), called latency Ilb. This is followed by the long-term outgrowth of LCLs expressing the EBNAs along with the LMPs, particularly the NFאB-activating LMP1, defining latency III. LCLs, however, express a broad distribution of LMP1 such that a subset of these cells expresses LMP1 at levels seen in latency Ilb, making it difficult to distinguish these two latency states. In this study, we performed mRNA-Seq on early EBV-infected latency IIb cells and latency III LCLs sorted by NFKB activity. We found that latency IIb transcriptomes clustered independently from latency III independent of $\mathrm{NF} \kappa \mathrm{B}$. We identified and validated mRNAs defining these latency states. Indeed, we were able to distinguish latency llb cells from LCLs expressing low levels of LMP1 using multiplex RNA-FISH targeting EBV EBNA2, LMP1, and human CCR7. This study defines latency IIb as a bona fide latency state independent from latency III and identifies biomarkers for understanding EBV-associated tumor heterogeneity. 


\section{IMPORTANCE}

EBV is a ubiquitous pathogen with $>95 \%$ of adults harboring a life-long latent

39 infection in memory B cells. In immunocompromised individuals, latent EBV infection

40 can result in lymphoma. The established expression profile of these lymphomas is

41 latency III, which includes expression of all latency genes. However, single cell analysis

42 of EBV latent gene expression in these lymphomas suggests heterogeneity where most

43 cells express the transcription factor, EBNA2, and only a fraction express the

44 membrane protein LMP1. Our work describes an early phase after infection where the

45 EBNAs are expressed without LMP1, called latency llb. However, LMP1 levels within

46 latency III vary widely making these states hard to discriminate. This may have

47 important implications for therapeutic responses. It is crucial to distinguish these states

48 to understand the molecular pathogenesis of these lymphomas. Ultimately, better tools

49 to understand the heterogeneity of these cancers will support more efficacious therapies

50 in the future. 


\section{INTRODUCTION}

Epstein-Barr Virus (EBV) is a large double-stranded DNA $\gamma$-herpesvirus that

63 establishes life-long latent infection in resting memory B cells. Despite robust immune

64 control in the vast majority of infected individuals, immune-compromised patients are at

65 high risk for EBV-driven B-cell lymphomas. A model for these lymphomas is EBV

66 infection and immortalization of primary human B cells in vitro into lymphoblastoid cell

67 lines (LCLs). Immortalized LCLs express all eight EBV latency proteins, consistent with

68 latency III gene expression, including the EBV nuclear antigen (EBNA) transcription

69 factors and the latent membrane proteins (LMPs), which are constitutively-active

70 receptor mimics (1-3).

71 However, EBV-infected B cells initially undergo a period of hyper-proliferation

72 characterized by expression of the EBNAs in the near absence of the LMPs, which is

73 called latency Ilb $(4,5)$. Early after infection, EBNA2 stimulates cellular proliferation by

74 inducing the host transcription factor c-Myc through coordination of its upstream

75 enhancer and chromatin looping (6). During this period, the cells are dependent upon

76 MCL-1 and BCL-2 for survival in the absence of $\mathrm{NF} \kappa \mathrm{B}$ signaling $(5,7)$. Elevated levels

77 of c-Myc early after infection antagonize LMP1 mRNA and protein expression (8). Low

78 LMP1 levels early after infection may function to evade CD8+ T-cell recognition as

79 LMP1-mediated NFKB activity promotes MHC-I expression and peptide presentation (9,

80 10). By two to three weeks post-infection, c-Myc levels wane, hyper-proliferation is

81 attenuated, and full expression of the LMPs, particularly LMP1-mediated NFkB activity, 
82 is observed (11). These cells rely on NFKB signaling for survival (12) and display a

83 distinct mitochondrial anti-apoptotic phenotype with up-regulation of BFL-1 $(5,7)$.

While latency III is characterized by full expression of the latent membrane

85 proteins, it has long been observed that LMP1 levels vary widely within an LCL

86 population. Flow cytometric analysis for LMP1 within bulk LCL populations shows an

$87 \sim 100$ fold range of LMP1 protein levels at single-cell resolution (13). This variable

88 expression appears to be important for LCL homeostasis as significantly elevated or

89 depleted LMP1 levels results in reduced proliferation and cells sorted for high or low

90 levels of LMP1 return to their full distribution within 18 hours of sorting $(10,13)$.

91 Therefore, LMP1 expression within an LCL population fluctuates widely on a single-cell

92 level and this wide distribution is important for LCL survival.

EBV is associated with several different lymphomas including Hodgkin's

94 Lymphoma, Burkitt Lymphoma and Post-Transplant Lymphoproliferative Disease

95 (PTLD). However, the viral latency gene expression in EBV-associated diseases are

96 typically very heterogeneous. To understand the latency gene expression pattern in

97 these diseases, immunohistochemical staining is employed to analyze the expression of

98 LMP1 and EBNA2 in patient biopsies. Staining patient biopsies has demonstrated

99 heterogeneity at the single cell level where many cells may be EBNA2-positive but

100 negative for LMP1 $(14,15)$. These cells are often quite common as recent studies in a

101 mouse model of EBV and Kaposi Sarcoma Herpes Virus (KSHV) co-infection also

102 identified a high frequency of EBNA2+/LMP1- cells (16). Due to the wide distribution of

103 LMP1 expression within a latency III LCL population, this technique does not allow for

104 distinguishing LMP1 low latency III LCLs from LMP1 low latency Ilb cells. 
We have previously demonstrated that latency IIb and latency III cells have

106 unique survival requirements and apoptotic regulation $(7,17,18)$. However, these

107 studies analyzed bulk LCL populations and did not address single-cell level differences.

108 In this study we address such single-cell heterogeneity by fluorescence-activated cell

109 sorting (FACS) sorting latency III LCLs based on surface ICAM-1 as a proxy for LMP1-

110 mediated NFKB activity. Using this sorting strategy, we explored whether latency Ilb

111 cells are unique from a subset of NFKB-low LCLs that express reduced levels of LMP1.

112 We also identified host transcriptomic markers of these latency states that are

113 expressed in a latency stage dependent manner, but independent of LMP1 expression

114 levels. Taken together, this work characterizes latency Ilb as a unique B-cell latency

115 state of EBV infection and identifies biomarkers that enables discrimination between

116 latency IIb and latency III. 


\section{RESULTS}

119 ICAM-1 is a proxy for LMP1-mediated NFKB target gene activation. We have 120 previously demonstrated that LMP1 levels are significantly lower early after EBV 121 infection of primary human B cells than in immortalized LCLs (5). However, it is also 122 known that LMP1 levels vary widely within an LCL population $(10,13)$. Due to the wide 123 distribution of LMP1 expression in an LCL population, we first asked how these levels 124 compare to early-infected proliferating latency Ilb cells. To assay this at the protein 125 level, we conducted FACS analysis on early proliferating latency Ilb cells (day 7 postinfection) and donor matched LCLs (>35 days post-infection) for ICAM-1 as a proxy for

127 LMP1 mediated NFKB activity (19). As described in Fig. 1A, a subset of LCLs display 128 similarly low levels of NFאB activity to latency Ilb cells, corroborating our previous data. 129 Therefore, we concluded that these cells likely express comparable levels of LMP1

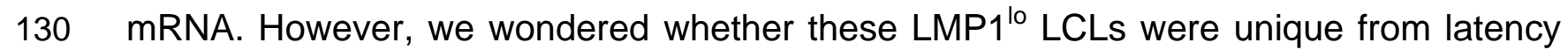
131 Ilb cells, or cells that were "stuck" in latency IIb. To test this, we sorted latency Ilb cells 132 to purity as well as the bottom, middle and upper 15\% of ICAM-1 expressing cells within 133 donor matched LCL populations (Fig. 1A). We used RT-qPCR analysis to validate that 134 ICAM-1 levels were similar between latency Ilb cells and ICAM-1 ${ }^{\text {lo }}$ LCLs and that ICAM1351 mRNA abundance increased with increasing ICAM-1 MFI (Fig. 1B). Importantly, 136 LMP1 mRNA abundance followed the same pattern as ICAM-1 (Fig. 1C). In fact, there 137 was a direct linear correlation between ICAM-1 and LMP1 mRNA abundance, thereby 138 validating our sorting strategy (Fig. 1D).

139 Generation and validation of RNA-Seq libraries from EBV early-infected and LCL 140 populations sorted on ICAM-1 level. We next generated RNA-sequencing libraries to 
141 asses global gene expression differences between these four populations: B cells 7

142 days post EBV infection (latency IIb) and LCLs with low, middle, or high levels of ICAM-

1431 (Fig. 1A). We first sought to validate our RNA-Seq libraries by querying the global

144 gene expression differences between ICAM-1 ${ }^{\text {lo }}$ and ICAM-1 ${ }^{\text {hi }}$ LCLs. Consistent with our

145 initial sorting and qPCR experiments, we found by GSEA analysis a significant

146 enrichment in $\mathrm{NF} \kappa \mathrm{B}$ targets in ICAM-1 ${ }^{\text {hi }}$ relative to ICAM-1 ${ }^{\text {lo }}$ LCLs (Fig. 2A). Indeed,

147 RNA-Seq coverage maps indicate that two well-described NFкB targets, TRAF1 and

148 A20, are expressed at higher levels in ICAM-1 ${ }^{\text {hi }}$ relative to ICAM-1 ${ }^{\text {lo }}$ LCLs (Fig. 2B). RT-

149 qPCR analysis confirmed the RNA-seq results (Fig. 2C) and these data suggest internal

150 validation of both our sorting approach and our RNA-Seq pipeline.

151 Host genes that distinguish EBV latency Ilb cells from ICAM-1 ${ }^{\text {lo }}$ LCLs are

152 associated with DNA replication. Our major goal in this study is to define the host

153 genes that distinguish early-infected latency Ilb cells from ICAM-1 ${ }^{\text {lo }}$ LCLs. Therefore, we

154 performed a direct comparison of the genes differentially expressed between these two

155 populations and identified 192 genes that were up-regulated in the transition from early-

156 infected latency IIb cells to ICAM-1 ${ }^{\text {lo }}$ LCLs relative and 216 genes down-regulated from

157 latency Ilb to ICAM-1 ${ }^{\text {lo }}$ LCLs (Fig. 3A and Supp. Table S1 and S2). We performed

158 GSEA for transcription factor motifs upstream of the differentially expressed genes and

159 found that E2F family transcription factors as well as MYC/MAX transcription factors

160 were significantly enriched in latency Ilb compared to ICAM-1 ${ }^{\text {lo }}$ LCLs (Fig. 3B). GSEA

161 also identified several gene ontology groups associated with DNA replication and mitotic

162 division as the hallmark of latency Ilb as compared to ICAM-1 ${ }^{\text {lo }}$ LCLs (Fig. 3C shows

163 representative plot). To validate these findings, we interrogated expression of the genes 
164 associated with DNA replication by qRT-PCR. We found that MCM10, RFC2, RAD51,

165 and PCNA were consistently, but not significantly, upregulated in latency Ilb as

166 compared to ICAM-1 ${ }^{\text {lo }}$ LCLs (Fig. 3D). Furthermore, this difference was not observed

167 between latency IIb and ICAM-1 ${ }^{\text {mid }}$ or ICAM-1 ${ }^{\text {hi }}$ LCLs. Given our inability to identify host

168 markers that distinguish latency Ilb from latency III from within this gene ontology group,

169 we next sought to query the RNA-Seq data more broadly to identify such markers.

170 EBV early-infected latency IIb cells are transcriptomically distinct from latency III

171 LCLs irrespective of ICAM-1/LMP1 levels. We next sought to assess whether the

172 transcriptome of latency Ilb cells varied significantly from the ICAM-1 sorted LCL

173 populations. We first generated a Pearson coefficient similarity matrix comparing the

174 expression profiles of all 16 samples. Day 7 latency Ilb transcriptomic profiles clustered

175 together independently of donor and the ICAM-1/LMP1 expression of the donor (Fig.

176 4A). The remaining clusters were comprised of the ICAM-1 ${ }^{\text {lo }}, \operatorname{ICAM}-1^{\text {mid }}$, and ICAM- $1^{\text {hi }}$

177 groups with each donor clustering independently from the others. These results were

178 further substantiated by unsupervised hierarchical clustering of the samples where we

179 found that day 7 latency Ilb cells clustered independently of latency III LCLs (Fig. 4B).

180 Therefore, gene expression differences between latency IIb and latency III cells are

181 greater than those between donors and also between latency IIb and any ICAM-1

182 sorted population.

K-means clustering of the gene expression data generated profiles uniquely

184 associated with latency IIb and latency III. Within these profiles, we identified

185 significantly differentially expressed genes based on a greater than 2-fold change and $186 \mathrm{p}<0.05$ in at least two of the three comparison (day 7 versus ICAM- $1^{\text {lo }}$, ICAM- $1^{\text {mid }}$, or 
187 ICAM-1 ${ }^{\text {hi }}$ LCLs). This analysis yielded 181 latency Ilb-specific and 282 latency III188 specific genes (Supp. Table S3). We chose four genes from each group with binary-like expression behavior to validate their specificity to latency IIb or latency III. Host 190 biomarkers of latency Ilb were CCR6, FCRL3, FCRL4, and TGFBR2. RNA-Seq coverage maps illustrate and qRT-PCR experiments validated IIb specificity of these

192 genes (Fig. 4C-D). Latency III biomarkers were CCR7, MGST1, DST, and TSC22D3 and these displayed similar binary-like gene expression behavior (Fig. 4E-F). surface-expressed, we chose to investigate their utility as protein biomarkers to distinguish latency IIb from latency III. Flow cytometry of CCR6 indicated a strong downregulation of surface expression comparing day 7 post infection to LCLs irrespective of fluorescence intensity (MFI) for CCR6 decreased significantly from day 7 to LCL (Fig.

204 day 7 to LCL (Fig. 5D-E), the percent positive cells only increased about two-fold (Fig.

206 distinguish between latency IIb and latency III expressing cells.

207 Multiplex RNA-FISH can distinguish latency Ilb from latency III. Given the

208 challenges of protein-based biomarker validation, we sought to use multiplex RNA 209 fluorescence in situ hybridization (RNA-FISH) to leverage our RNA-based biomarker 
210 discovery approach. As detailed in Fig. 4E, the mRNA expression of CCR7 strongly 211 correlated with latency III independent of ICAM-1/LMP1 levels. CCR7 was also the most

212 highly abundant latency III-specific mRNA. Therefore, we designed probes to detect 213 CCR7 mRNA along with EBNA2 and LMP1 mRNAs. Our hypothesis would predict that 214 latency Ilb cells (EBNA2 $2^{+} / \mathrm{LMP}^{-}{ }^{-}$) would be CCR7-negative and that latency III cells 215 would be CCR7-positive irrespective of LMP1 level. We tested this hypothesis in sorted, 216 proliferating day 7 (latency $\mathrm{llb}$ ) infected cells and LCLs with resting B cells and the EBV-

217 negative B-lymphoma cell line, BJAB, as negative controls (Fig. 6A). EBNA2 218 expression was robust in EBV-infected day 7 cells and LCLs as compared to resting B 219 cells and BJABs (Fig. 6A-B). LMP1 expression was low in day 7 and higher, but 220 heterogeneous, in LCLs, as expected (Fig. 6A-C). CCR7 levels were low in EBNA2+ 221 day 7 cells and significantly higher in LCLs independent of LMP1 level (Fig. 6D-E). 222 Indeed, the full heterogeneity of LMP1 expression levels in latency III is visualized in 223 Fig. 6E where all cells are EBNA2-positive and CCR7-positive. Thus, CCR7 mRNA is a 224 reliable host transcriptomic marker of EBV latency III. 


\section{DISCUSSION}

In this study, we identified host biomarkers that distinguish EBV latency Ilb from EBV displays a latency Ilb phenotype where the viral EBNA proteins are expressed in the near absence of the LMPs $(5,20)$. However, later during primary infection latency III

231 is observed where the EBNAs and LMPs are all expressed as in LCLs. Broad distribution of LMP1 within latency III populations makes these cells difficult to distinguish. As many EBV-positive tumors display cellular LMP1 heterogeneity $(14,15)$,

234 it is important to determine whether these EBNA+/LMP1- cells are latency Ilb or latency

235 III as their immune recognition and response to chemotherapy may vary depending on 236 viral gene expression $(7,10)$.

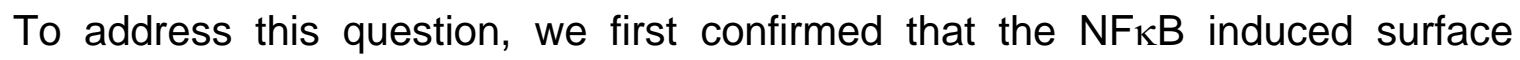

239 mRNA levels (19). We confirmed the broad range of LMP1/NFkB expression in latency

240 III as observed by others $(10,13)$ and found a significant overlap of ICAM-1 surface

241 levels between the latency Ilb early-infected cells and ICAM-1 ${ }^{\text {lo }}$ LCLs. Through FACS

242 sorting coupled with RNA-sequencing, we found that the major determinant between

$243 \mathrm{LMP1}^{\text {lo }}$ and $\mathrm{LMP}^{\text {hi }}$ expressing LCLs is indeed NFKB signaling with a small component

244 of cell cycle regulation through E2Fs. Importantly, we found that latency Ilb gene

245 expression profiles clustered distinct from latency III irrespective of LMP1 level or donor

246 from which they were generated. Thus, latency Ilb is a bona fide latency state.

We identified and validated four latency IIb and latency III specific host mRNAs

248 that were differentially regulated between the states. CCR6, FCRL4, FCRL3 and 
TGFBR2 were specific to latency Ilb while CCR7, MGST1, DST and TSC22D3 were

250 specific to latency III. Interestingly, CCR7 was one of the first genes demonstrated to be

251 induced by EBV, originally being called EBI-1 (21). However, surface expression of

252 CCR6 and CCR7 did not fully distinguish latency IIb from latency III. For this reason, we

253 turned to multiplexed RNA-FISH to simultaneously measure LMP1, EBNA2 and CCR7

254 mRNA levels in single cells. This approach coupled with a multinomial regression model

255 allowed us to predict whether an infected cell was latency Illb or latency III.

While protein-based expression analysis by immuno-histochemistry (IHC) is the

257 gold standard in pathology labs, multiplex RNA-FISH is a promising new approach to

258 decipher cellular heterogeneity in tumors $(22,23)$. This approach is equally sensitive

259 compared to $\mathrm{IHC}$ but lacks the limitations of antibody specificity and sensitivity $(24,25)$.

260 Indeed, multiplex RNA-FISH overcomes the issue of protein epitope variation or antigen

261 retrieval by tiling probes for the target gene across the entire length of the mRNA. In our 262 studies, multiplexing probes with distinct fluorophores enabled the detection of both viral 263 and host mRNAs at single cell resolution.

264 EBV-positive lymphomas in immune-suppressed patients have been 265 characterized to display latency III gene expression (EBNA+/LMP+) (20). However, 266 several early pathology studies of EBV-positive PTLD and HIV lymphomas as well as 267 more recent mouse models describe a significant EBNA+/LMP- cell population $(14,15)$.

268 In a cord blood mouse model of EBV infection, EBNA2+/LMP1- cells were observed at a 269 high frequency while latency III cells were rarely detected. This was hypothesized to be 270 due to the increased immunogenicity of latency III cells (26). Similarly, a recent study 271 using a mouse model of EBV/KSHV co-infection, latency Ilb cells were detected at a 
272 high frequency (16). The pathophysiological relevance of latency Ilb therefore supports

273 our study to define latency-distinguishing host markers.

$274 \quad$ Autologous and allogeneic T-cell therapies targeting MHC-restricted viral

275 antigens are used in the treatment of EBV-associated PTLD (27-33). These products

276 are typically highly enriched for CD8+ cytotoxic T cells and therefore, proper EBV

277 antigen presentation through MHC class I within these tumors is likely important for a

278 robust clinical response. As LMP1 expression in a latency III B cell cycles between sub-

279 populations that are $\mathrm{LMP} 1^{\text {hi }}$ and highly sensitive to CD8+ T-cell killing and those that 280 are $\mathrm{LMP}^{10}$ and much less sensitive (10), it will be important to distinguish whether

281 EBNA2+/LMP1- cells within PTLD tumors are fixed LMP1 $1^{10}$ latency llb cells or are

282 latency III cells cycling between low and high LMP1 states. PTLD tumors with persistent 283 latency Ilb infection may be more difficult to treat with T-cell therapies than latency III-

284 predominant PTLD. This remains to be tested by correlating EBV latency type in PTLD 285 tissue with response to T-cell therapy.

Recent clinical studies have led to the development of LMP-specific CTLs for the 287 treatment of EBV latency lla tumors (LMP+/EBNA-) (34-36). For EBV-associated PTLD 288 with predominately latency III gene expression, LMP-specific CTLs would be expected 289 to have clinical efficacy and, indeed, a clinical trial is underway (37). In light of our 290 findings regarding latency $\mathrm{Ilb}$, it remains pertinent to consider screening these tumors 291 for LMP1 expression and perhaps excluding tumors that display a latency llb expression 292 phenotype. Coupling the host biomarkers that we have identified together with the viral 293 EBNA2 and LMP1 using multiplex RNA-FISH could provide significant predictive power 294 in screening these tumors for efficacy using T-cell therapies and chemotherapeutics. 


\section{MATERIALS AND METHODS}

Cell lines, culture conditions, and viruses

Peripheral Blood Mononuclear Cells (PBMCs) were obtained from whole blood from the Gulf Coast Regional Blood Center (Houston, TX) via centrifugation over a

300 Ficoll Histopaque-1077 gradient (Sigma, H8889). The B95-8 strain of Epstein-Barr Virus 301 was generated from the B95-8 Z-HT cell line as previously described (38). Virus 302 infections were performed by adding either $100 \mu \mathrm{L}$ of filtered B95-8 Z-HT supernatant to $30310^{6}$ PBMCs or $500 \mu \mathrm{L}$ of B95-8 Z-HT per $10^{6}$ B-cells, as determined by FACS. 15\% (primary B cells) fetal bovine serum (FBS) (Corning), $2 \mathrm{mM} \mathrm{L-Glutamine}$ 306 (Invitrogen), $100 \mathrm{U} / \mathrm{mL}$ penicillin, $100 \mu \mathrm{g} / \mathrm{mL}$ streptomycin (Invitrogen). All cells were 307 maintained at $37^{\circ} \mathrm{C}$ in a humidified incubator with $5 \% \mathrm{CO}_{2}$.

\section{Flow Cytometry and Sorting}

To track cellular division, cells were stained with CellTrace Violet (Invitrogen, 310 C34557), a fluorescent proliferation-tracking dye. For analytical panels, $10^{6}$ PBMCs on

311 day 7 post-infection with EBV B95-8 or $10^{6}$ LCLs were washed once with FACS buffer 312 (PBS $+5 \%$ FBS) and stained with the following antibodies in isolation or in combination

313 for $30-60$ minutes in the dark at $4^{\circ} \mathrm{C}$ : ICAM-1 PE (BioLegend „\#353106), CCR6 314 PE/Dazzle (BioLegend, 353430), CCR7 PE/Dazzle (BioLegend, 353236), or CD19 APC 315 (BioLegend, 302212). After incubation, cells were washed once with FACS buffer and 31610,000 blank counting beads (Spherotech, \#ACBP-50-10) were added to each tube. 317 Data was collected on a BD LSRFortessa and 1000 blank beads were used as the 
318 stopping gate. All samples were stained and analyzed via FACS at the same time to

319 ensure consistency in analysis. Marker positivity was determined using matched

320 fluorescence minus one control.

$321 \quad$ For sorting experiments, proliferating cells were sorted to purity using CD19 APC

322 (BioLegend, 302212) positivity as well as a dilution of CellTrace Violet $\left(\mathrm{CD}_{19} / \mathrm{CTV}^{\mathrm{lo}}\right)$ on

323 a MoFlo Astrios Cell Sorter at the Duke Cancer Institute Flow Cytometry Shared

324 Resource. LCLs were sorted to purity after staining with ICAM-1 PE (BioLegend,

325 \#353106) and gated for the bottom, middle and upper 15\% of ICAM-1 expressing cells.

326 RNA-Sequencing and Analysis

Whole RNA from sorted early EBV infected latency Ilb B cells and from sorted

328 donor matched LCLs were isolated using a RNeasy-Kit (Qiagen, \#74104). mRNA

329 sequencing libraries were prepared using a Kappa Stranded RNA-Seq Library

330 Preparation Kit (Kappa Biosystems, KR0934) and sequenced on an Illumina Hiseq 4000

331 at the Duke University Sequencing and Genomics Shared Core Facility. Resulting

332 single-end, unpaired reads were aligned to the human genome (hg38) using Hisat2

333 (39). Resulting BAM files were converted to SAM files using samtools and transcripts

334 were assembled using Stringtie. Assembled transcripts were quantified using the $\mathrm{R}$

335 package Ballgown. Normalized RPKMs were exported from Ballgown and used for 336 heatmap visualization and $\log _{2}(\mathrm{RPKM}+1)$ calculations. Statistical significance and false-

337 positivity were determined using ballgown. Heatmaps were generated using Morpheus

338 from the Broad Institute (https://software.boradinstitute.org/morepheus) and similarity

339 matrices were created using the $R$ package pheatmap (https://CRAN.R- 
340 project.org/package=pheatmap). RNA-sequencing coverage maps were generated

341 using UCSC Genome Browser in a Box (GBiB) (40).

RNA Isolation, RT-qPCR and Primers Used

Total RNA from sorted EBV infected early latency Ilb proliferating B cells or

344 sorted LCLs was isolated using an RNAeasy kit (Qiagen, \#74104) according to the

345 manufacturer's instructions. One microgram of total RNA was reverse transcribed into

346 cDNA using the High-Capacity cDNA Reverse Transcription Kit (Applied Biosystems,

347 4368814) according to the manufacturer's instructions. Resulting cDNA was diluted in

348 ultra-pure $\mathrm{H}_{2} \mathrm{O}$ and $5 \mathrm{ng}$ per reaction was used for RT-qPCR via SYBR green

349 (Quantabio, cat\# 95054) detection method. Relative expression was calculated using

350 the $\triangle \triangle C T$ method using SETDB1 as an endogenous control. The following table lists all

351 primers used for RT-qPCR in this study:

352

\begin{tabular}{|c|c|c|}
\hline Gene Name & Forward (5'>3') & Reverse (5'->3') \\
\hline ICAM-1 & ATGCCCAGACATCTGTGTCC & GGGGTCTCTATGCCCAACAA \\
\hline LMP1 & AATTTGCACGGACAGGCATT & AAGGCCAAAAGCTGCCAGAT \\
\hline TRAF1 & TCCTGTGGAAGATCACCAATGT & GCAGGCACAACTTGTAGCC \\
\hline A20 & TTGTCCTCAGTTTCGGGAGAT & ACTTCTCGACACCAGTTGAGTT \\
\hline CCR6 & TTCAGCGATGTTTTCGACTCC & GCAATCGGTACAAATAGCCTGG \\
\hline FCRL3 & GTAAGAAGCCTGGGTAGAAAGAC & GCTGCACAGTAGTATCTCCCTG \\
\hline FCRL4 & TCTTCAGACTCCTTAATCCTG & CCAAGTATATTTCACAGCAGTC \\
\hline TGFBR2 & AAGATGACCGCTCTGACATCA & CTTATAGACCTCAGCAAAGCGAC \\
\hline CCR7 & ATTTGTGTGGGCCTACTG & TCATGGTCTTGAGCCTCTTGA \\
\hline
\end{tabular}




\begin{tabular}{|c|c|c|}
\hline MGST1 & ATGACAGAGTAGAACGTGTACGC & TACAGGAGGCCAATTCCAAGA \\
\hline DST & CTACCAGCACTCGAACCAGTC & GCCGAAGCTAATGCAAGAGTTG \\
\hline TSC22D3 & AACACCGAAATGTATCAGACCC & TGTCCAGCTTAACGGAAACCA \\
\hline MCM10 & CCCCTACAGACGATTTCTCGG & CAGATGGGTTGAGTCGTTTCC \\
\hline RAD51 & CAACCCATTTCACGGTTAGAGC & TTCTTTGGCGCATAGGCAACA \\
\hline PCNA & CCTGCTGGGATATTAGCTCCA & CAGCGGTAGGTGTCGAAGC \\
\hline RFC2 & GTGAGCAGGCTAGAGGTCTTT & TGAGTTCCAACATGGCATCTTTG \\
\hline SETDB1 & TCCATGGCATGCTGGAGCGG & GAGAGGGTTCTTGCCCCGGT \\
\hline
\end{tabular}

\section{RNA-FISH}

RNA-FISH was conducted using the Advanced Cell Diagnostics (ACD) RNA SCOPE Multiplex Fluorescent v2 Assay (Advanced Cell Diagnostics, \#323100). In brief, 357 resting $B$ cells isolated from peripheral blood (BD IMAG Human B Lymphocyte 358 Enrichment Set - DM, BD \#558007), sorted latency Ilb proliferating B cells on day 7 dpi and LCLs were washed once in PBS, fixed in 10\% neutral buffered formalin for 1 hour 360 at $37^{\circ} \mathrm{C}$, washed again in PBS and resuspended in $70 \% \mathrm{EtOH}$ before being cytospun 361 onto glass slides using a Cyto-Tek Sakura table-top cytofuge at $\sim 735 \mathrm{~g}$ for 22 mins. 362 Slides were dried for 20 mins before being fixed in an ethanol gradient of $50 \%, 70 \%$ and $363100 \% \mathrm{EtOH}$ for 5 mins each. Slides were stored overnight at $-20^{\circ} \mathrm{C}$ in $100 \% \mathrm{EtOH}$ 364 before being dried and having a hydrophobic barrier applied to the slide using an 365 ImmuEdge pen (Vector, $\mathrm{H}-4000)$. Samples were first treated with peroxide for 10 mins 366 at RT to quench endogenous peroxidase. After peroxide treatment, cells were treated 367 with ACD protease III for 30 mins at $40^{\circ} \mathrm{C}$ before proceeding to the standard RNA- 
SCOPE multiplex fluorescent V2 assay protocol, performed to the manufacturer's

369 instructions. Cells were stained with a probe mixture containing HHV4-LMP1-C1

370 (Advanced Cell Diagnostics, ref\#414681), HHV4-EBNA2-C2 (Advanced Cell

371 Diagnostics, ref\#547771-C2), and either Hs-CCR7-C3 (Advanced Cell Diagnostics,

372 ref\#410721-C3). After hybridization the signal was amplified and conjugated to either

373 Fluorescein, Cy3, or Cy5 Perkin Elmer TSA Secondaries (Perkin Elmer

374 NEL741E001KT, NEL744001KT and NEL745001KT, respectively). Slides were stained

375 with DAPI before being mounted with ProLong Gold antifade (Invitrogen, P10144).

376 Slides were dried for 30 mins at RT before being moved to $4^{\circ} \mathrm{C}$ for long-term storage.

377 All images were acquired on a Zeiss 780 Upright Confocal Microscope and resulting 378 images were analyzed with Fiji.

379 Fiji Image Analysis

Images were processed using in-house Fiji macros. The macro performs the

381 following functions: For each sample the DAPI image and corresponding fluorescent 382 channel image are simultaneously imported into Fiji. A Gaussian Blur $(\sigma=2)$ is applied 383 to the DAPI image and then an Otsu threshold is applied. The DAPI image is then 384 converted to binary and the watershed function is then applied to distinguish potentially 385 overlapping nuclei. A threshold is then applied to the fluorescent channel image (auto 386 for fluorescein and Cy5, minimum for Cy3). The DAPI image is subsequently selected 387 and the Fiji Set Measurements window is utilized to report the area, mean, minimum 388 and maximum intensity redirected to the fluorescent channel image. Fiji Analyze 389 particles is then used to determine the intensity of foci in the fluorescent channel image 390 that lie within boundaries identified by the DAPI channel image. 
Once the macro had been applied to all images for all fluorescent channels all of

392 the raw data is curated. The expression of day 7 cells and LCLs stained with positive

393 and negative control probes provided by the manufacturer (Advanced Cell Diagnostics,

394 REF\#321801 and 321831, respectively) were plotted on a histogram and positivity

395 thresholds were set at the point where the positive and negative control histograms

396 intersect (data not shown). For EBNA2-Cy3, a minimum threshold is used allowing for

397 harsh discrimination between EBV+ and EBV- cells. For LMP1-fluorescein and CCR7-

398 Cy5, to be more tolerant of "low" expression, a less harsh "automatic" thresholding 399 method was used.

$400 \quad$ Having established cutoffs for EBNA2, the data was subsequently curated to only 401 report LMP1 and CCR7 expression in cells that were positive EBNA2 mRNA to ensure 402 that we analyzed only EBV infected cells. Due to the non-gaussian distribution of this 403 positive signal, a Mann-Whitney non-parametric t-test was used to determine statistical 404 significance.

\section{DATA AVAILABILITY}

406 The RNA-sequencing data will be uploaded to Gene Expression Omnibus (GEO) 407 under accession number XXXX.

\section{ACKNOWLEDGMENTS}

409 This work was supported by National Institute of Health (NIH) grants R01410 DE025994 (to M.A.L.), T32-CA009111 (to J.E.M., J.D and A.M.P.), and F31-CA180451 411 (to A.M.P.) and F31-DE027875 (to J.D.). Additional funding came from the Duke CFAR, 412 and NIH-funded program (grant 5P30-Al064518). 
The authors would like to thank Dr. Michael Cook, Nancy Martin, Lynn Martinek

414 and the Duke Cancer Institute Shared Flow Cytometry core facility for invaluable

415 assistance with flow cytometry and cell sorting. We would also like to thank Dr. Lisa

416 Cameron, Dr. Yasheng Gao and the Duke Light Microscopy core facility for help with

417 confocal microscopy. We would also like to thank the Duke Sequencing and Genomic

418 Technologies core facility for help with mRNA sequencing. Lastly, we would like to

419 thank Dr. Dirk Dittmer, Justin Landis, Dr. Lorenzo Zaffiri, Dr. Elizabeth Pavlisko,

420 Francine Kelley, Andrew Nagler, Dr. Scott Palmer and Daniel Leibel for helpful

421 discussions during the drafting of this manuscript.

\section{AUTHOR CONTRIBUTIONS}

423 J.E.M, A.M.P., and M.A.L. conceived and designed research experiments. J.E.M.

424 performed buffy coat isolations from peripheral blood, EBV infections, all bioinformatic

425 analysis of RNA-sequencing data, RT-qPCR validation of RNA-sequencing, FACS

426 analysis of RNA-seq targets, and RNA-FISH. J.D. and L.J.S. prepared mRNA

427 sequencing libraries. A.M.P. performed the initial infection, sorting, and RNA isolation.

428 J.E.M. and M.A.L. wrote and all authors edited the manuscript. 
A
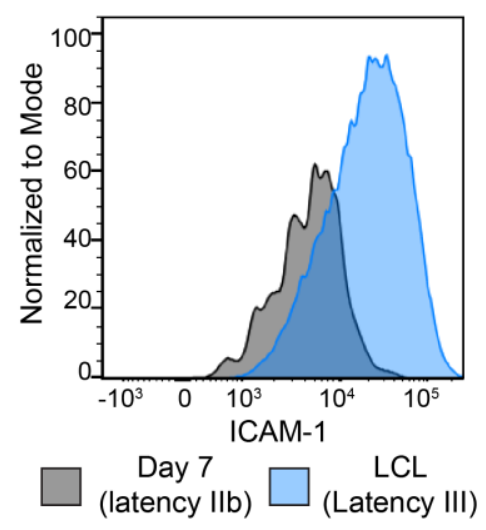

B

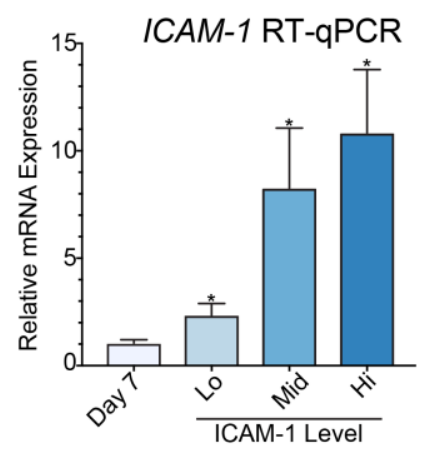

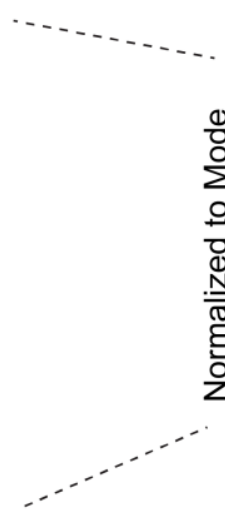

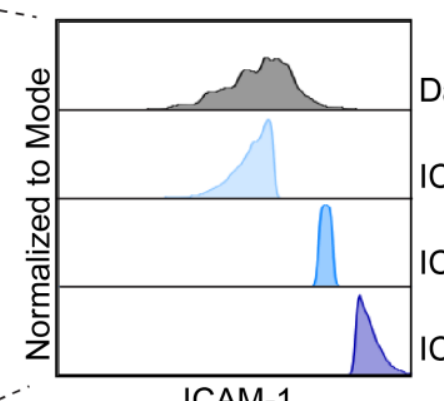

Day 7

Mean Fluorescence

Intensity

4721

ICAM-1 ${ }^{10} \mathrm{LCL}$

3831

23989

75527

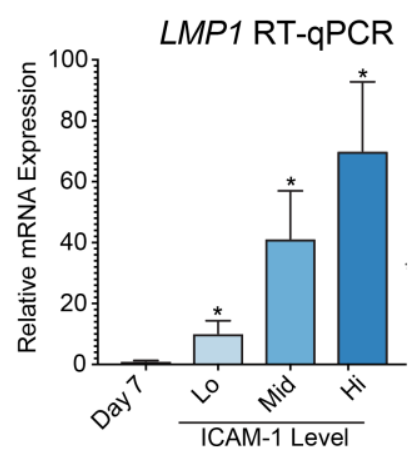

D $\quad L M P 1$ vs ICAM-1 Expression

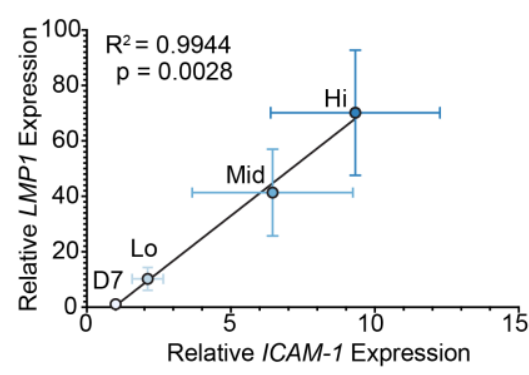

Figure 1: Using ICAM-1 as a proxy for LMP1 expression and LMP1-mediated NFKB signaling A) FACS analysis for ICAM-1 as a proxy for LMP1-mediated NFKB activity of day 7 dpi EBV infected latency Ilb proliferating B-cells and donor matched LCLs. Offset plot shows sorting groups of latency $\mathrm{Ilb}$ as well as the bottom, middle and upper $15 \%$ of ICAM-1 expressing LCLs with corresponding MFI B) RT-qPCR for ICAM-1 in sorted groups. Each bar represents the average of six independent matched donors. C) RTqPCR for LMP1 in sorted groups. Each bar represents the average of six independent matched donors. D) Correlation between LMP1 RT-qPCR expression and ICAM-1 RTqPCR expression. ${ }^{*} p<0.05,{ }^{* *} p<0.01,{ }^{* *} p<0.001$ by student's pairwise t-test. All error bars denote SEM. 

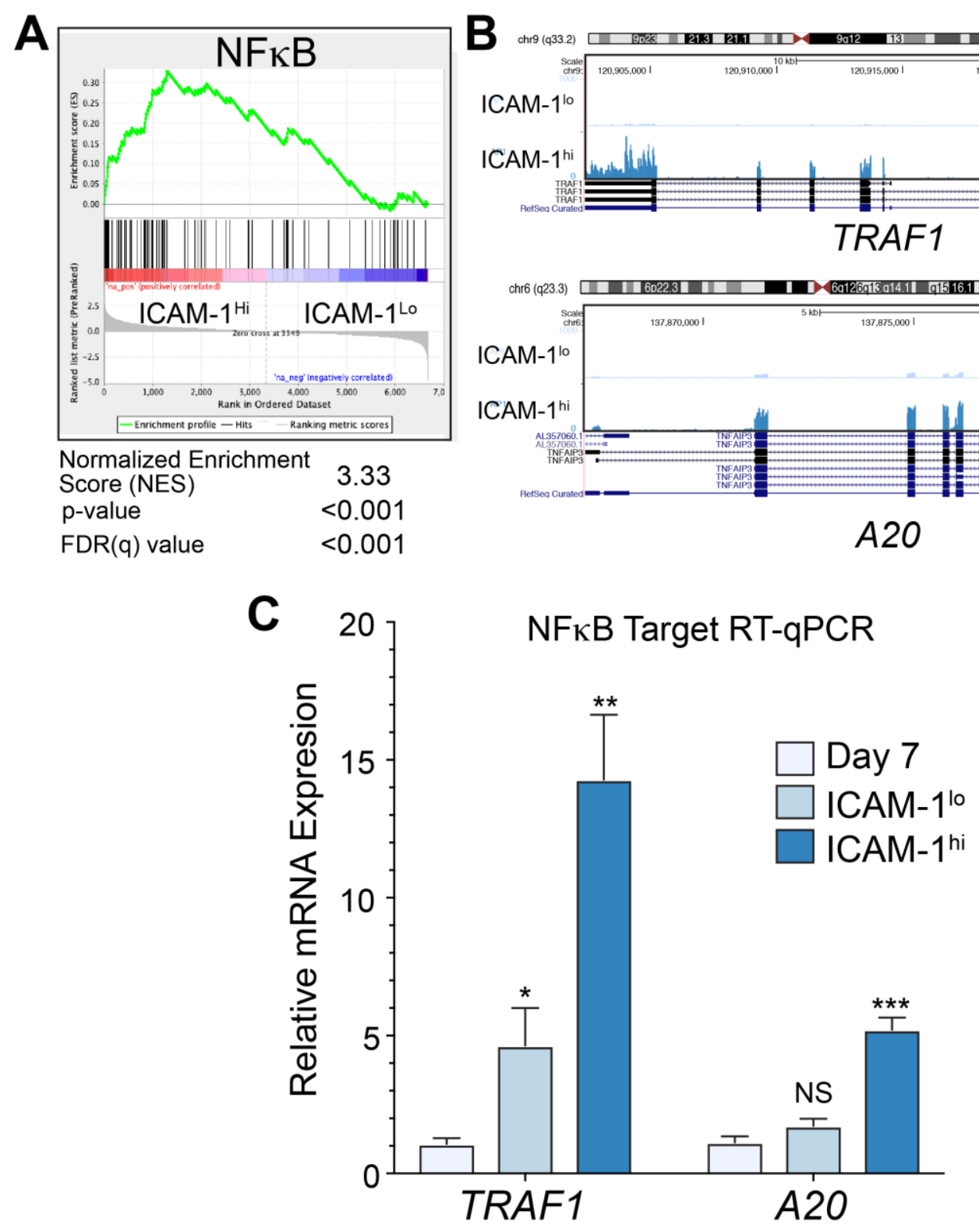
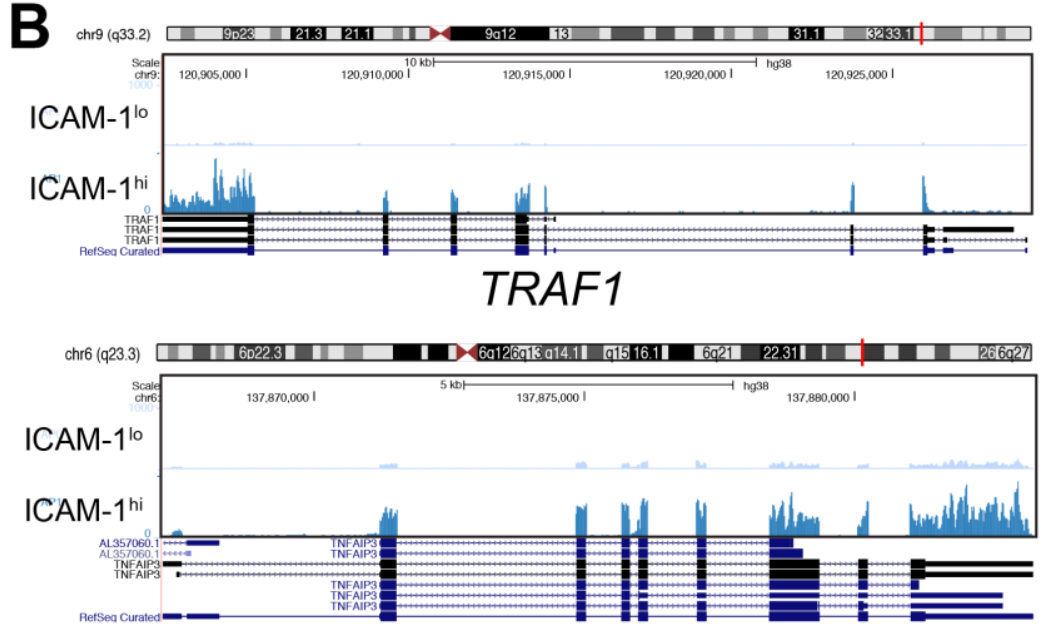

A20
443
Figure 2: LCL populations are homogeneous despite wide a wide LMP1/NFKB distribution A) Motif Pre-Ranked GSEA analysis between ICAM-1 ${ }^{\text {lo }}$ and ICAM- $1^{\text {hi }}$ expressing LCLs. B) RNA-seq coverage map at known NFKB targets TRAF1 and A20 for ICAM- $1^{10}$ and ICAM- ${ }^{\text {hi }}$ LCLs C) RT-qPCR for TRAF1 and A20 in donor matched day 7 dpi EBV infected proliferating latency Ilb cells and ICAM- $1^{10}$ or ICAM- $1^{\text {hi }}$ LCLs. Each bar represents the average of six independent matched donors. ${ }^{*} p<0.05,{ }^{* *} p<0.01,{ }^{* * *}$ $p<0.001$ by student's pairwise t-test. All error bars denote SEM. 

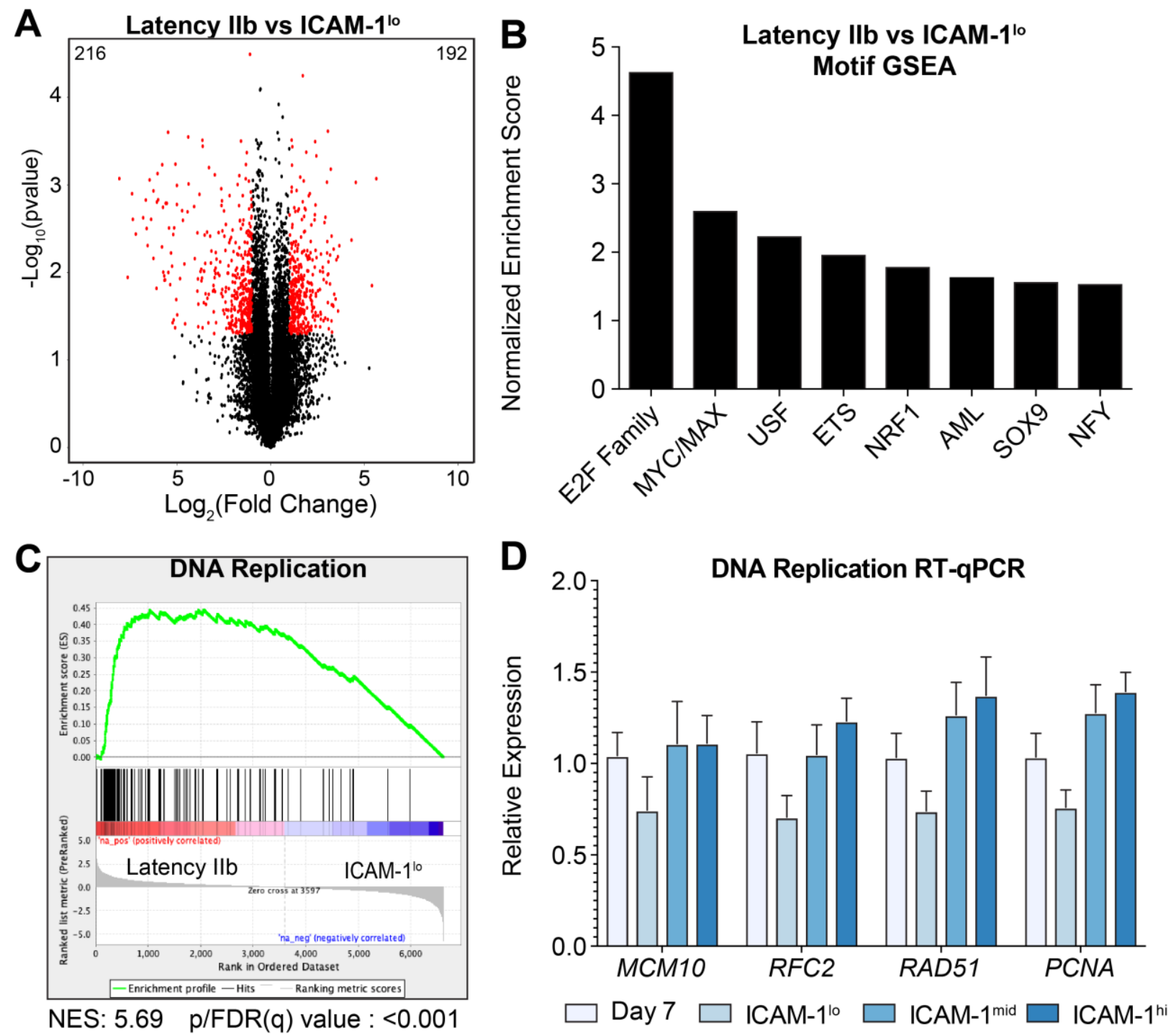

Figure 3: Latency $\mathrm{Ilb}$ is defined by hyper-proliferation and enhanced DNA replication A) Volcano plot of gene expression between latency IIb and ICAM-1 ${ }^{10} \mathrm{LCLs}$. Significantly regulated genes are indicated with red dots and have $p<0.05$ and a $\log _{2}$ (Fold Change) of greater than 1 or less than negative 1. The number in the top left indicates the number of significantly regulated genes in latency $\mathrm{llb}$ and the number in the top right denotes the number of significantly regulated genes for ICAM- $1^{10}$ B) Preranked motif GSEA analysis between latency Ilb and ICAM-1 ${ }^{10}$ LCLs C) Motif Preranked GSEA between latency Ilb and ICAM-1 $1^{10}$ LCLs for DNA replication D) RT-qPCR between latency IIb and ICAM-1 ${ }^{10}$ LCLs for DNA-replication genes. Each bar represents the average of six independent donors. Numbers on top of bars indicate the number of times this motif was listed by GSEA. ${ }^{*} p<0.05,{ }^{* *} p<0.01,{ }^{* * *} p<0.001$ by student's pairwise t-test. All error bars denote SEM. 
A

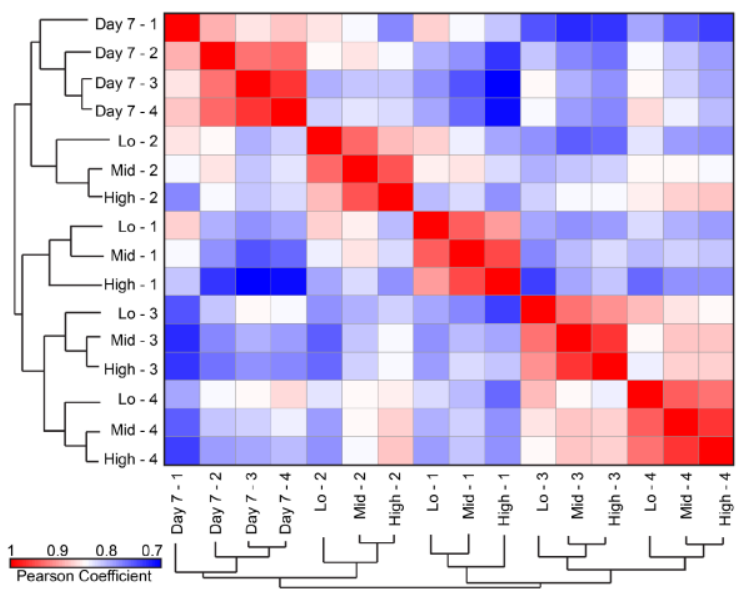

C

Latency Ilb Marker Coverage Maps
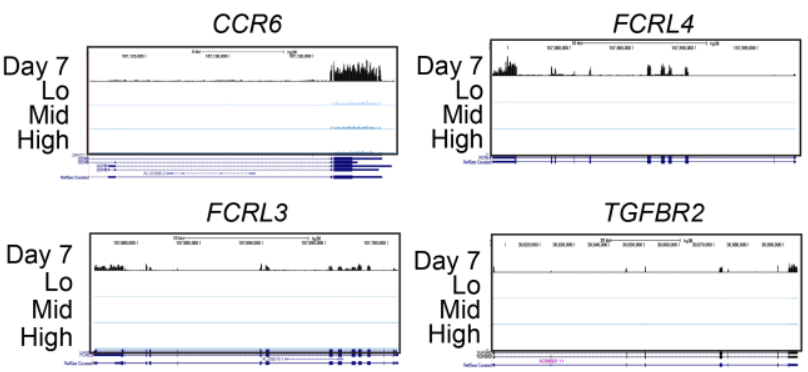

$\mathbf{E}$

Latency III Marker Coverage Maps
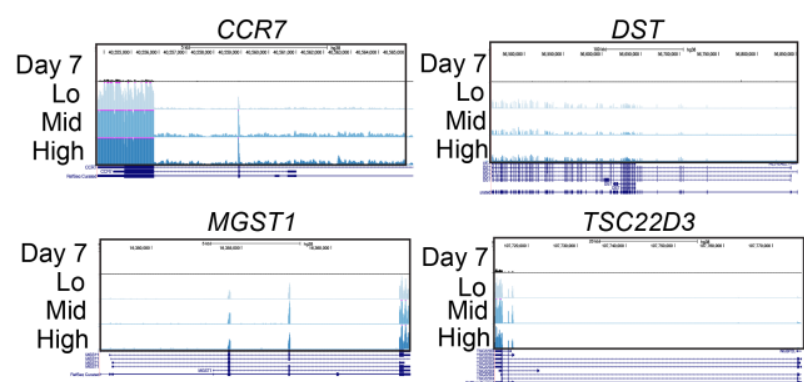

B

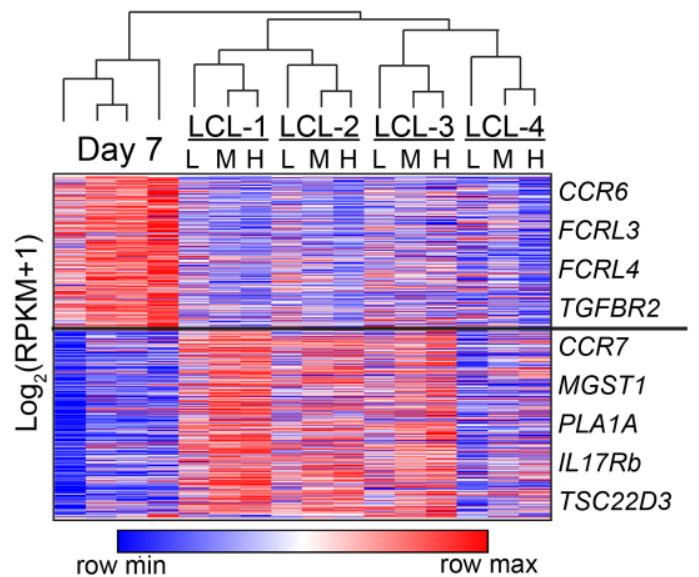

D

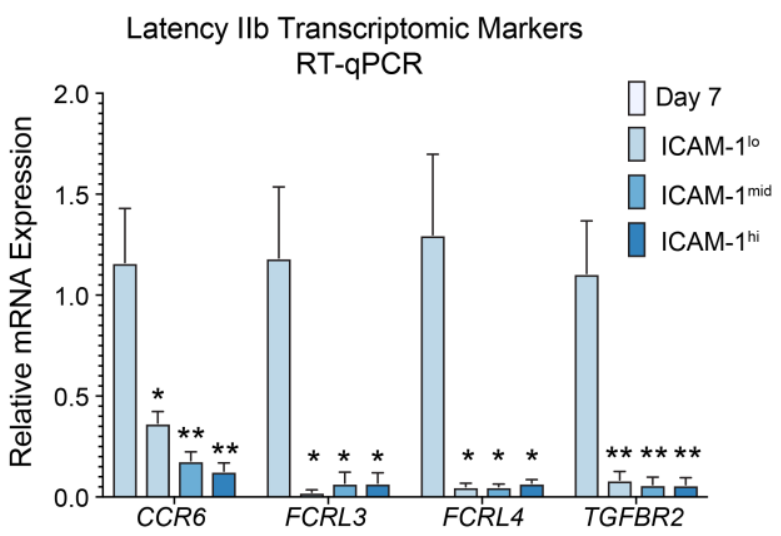

$\mathbf{F}$

Latency III Transcriptomic Markers RT-qPCR

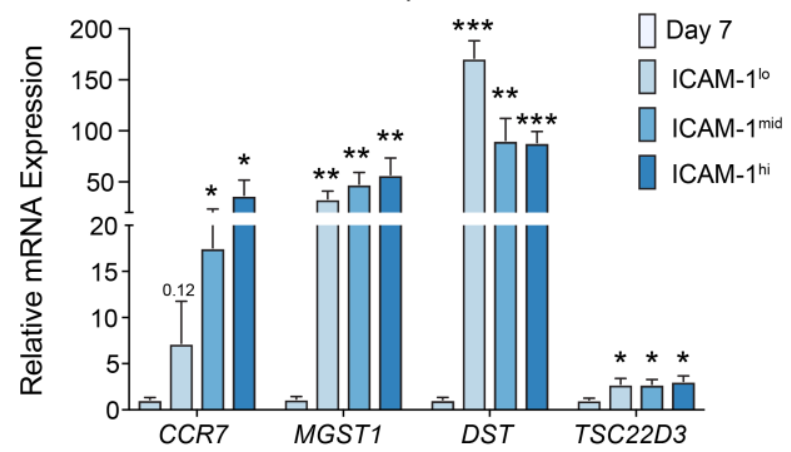

Figure 4: Latency IIb clusters uniquely from latency III independent of donor and both states contain transcriptionally unique host markers A) Pearson coefficient similarity matrix and hierarchical clustering between all samples used for RNAsequencing B) Gene expression heatmap with hierarchical and k-means clustering of gene expression data from RNA-sequencing C) RNA-sequencing coverage maps for latency Ilb specific identified genes D) RT-qPCR validation of latency Ilb specific genes E) RNA-sequencing coverage maps for latency III specific identified genes E) RT-qPCR validation of latency III specific genes. Each bar represents the average of six independent matched donors. ${ }^{*} p<0.05,{ }^{* *} p<0.01,{ }^{* * *} p<0.001$ by student's pairwise ttest. All error bars denote SEM. 
A
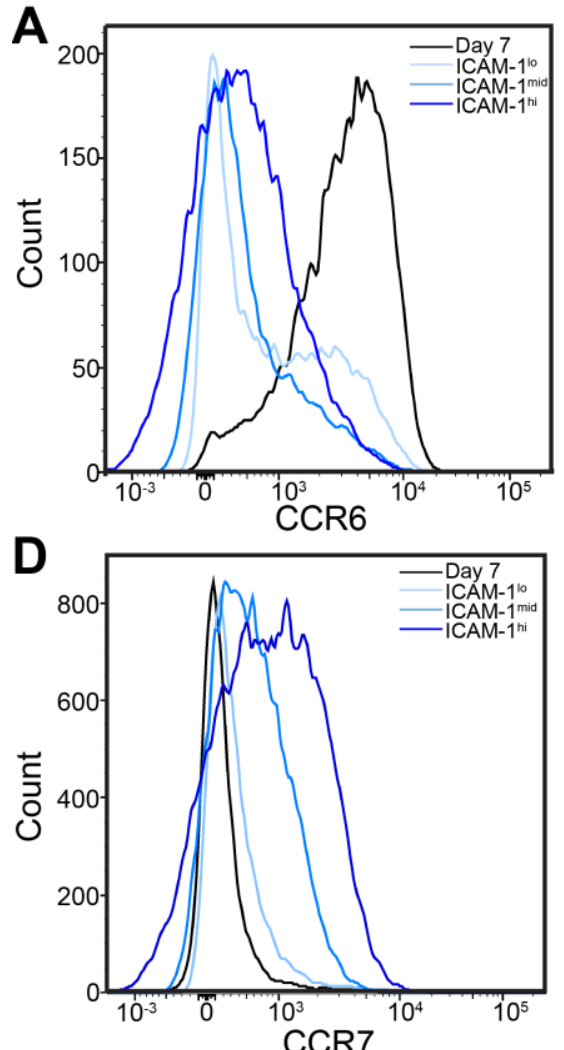

B

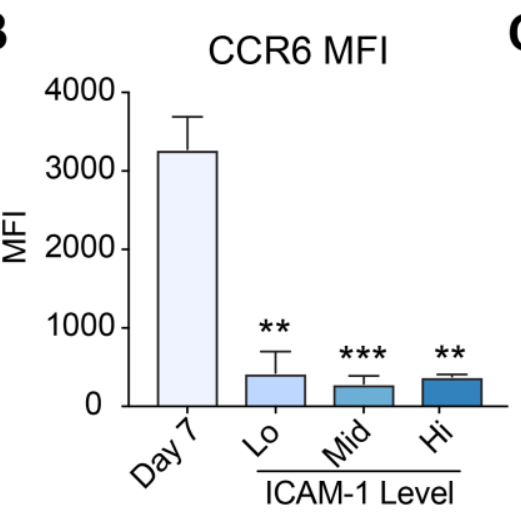

$E$

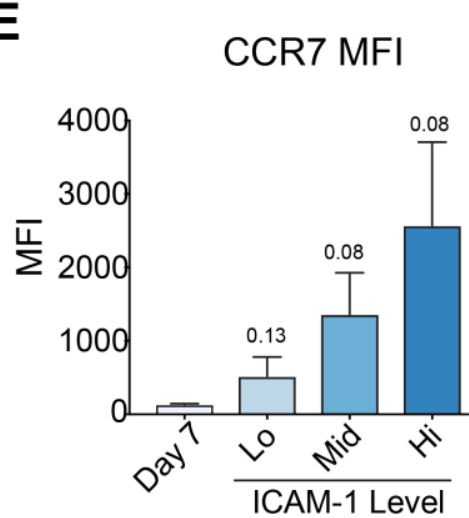

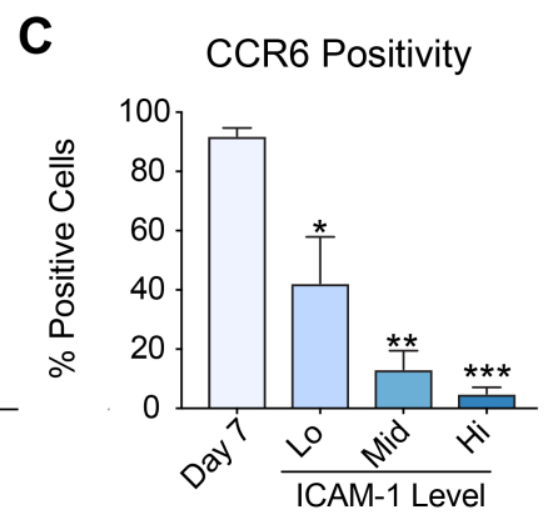

$\mathbf{F}$

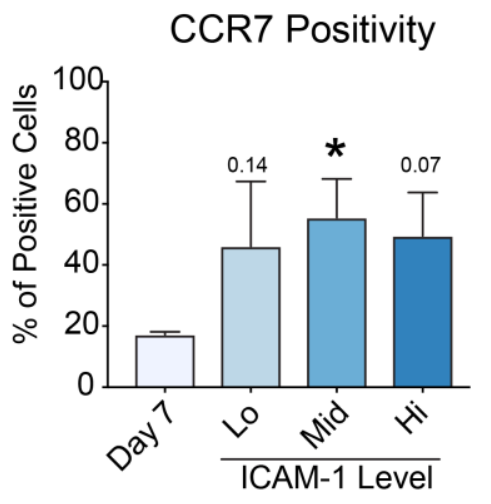

Figure 5: Protein validation of transcriptional markers reveals non-binary latency specificity A) FACS analysis for CCR6 in day 7 latency llb proliferating B cells and latency III LCLs stratified by ICAM-1 expression B) Quantification of mean fluorescence intensity of CCR6 expression from A C) Percentage of CCR6 positive cells from A D) FACS analysis for CCR7 in day 7 latency Ilb proliferating B cells and latency III LCLS stratified by ICAM-1 expression E) Quantification of mean fluorescence intensity of CCR7 expression from D F) Percentage of CCR6 positive cells from D. Each bar represents the average of 3 independent donors ${ }^{*} p<0.05,{ }^{* *} p<0.01,{ }^{* * *} p<0.001$ by student's pairwise t-test. All error bars denote SEM. 
A
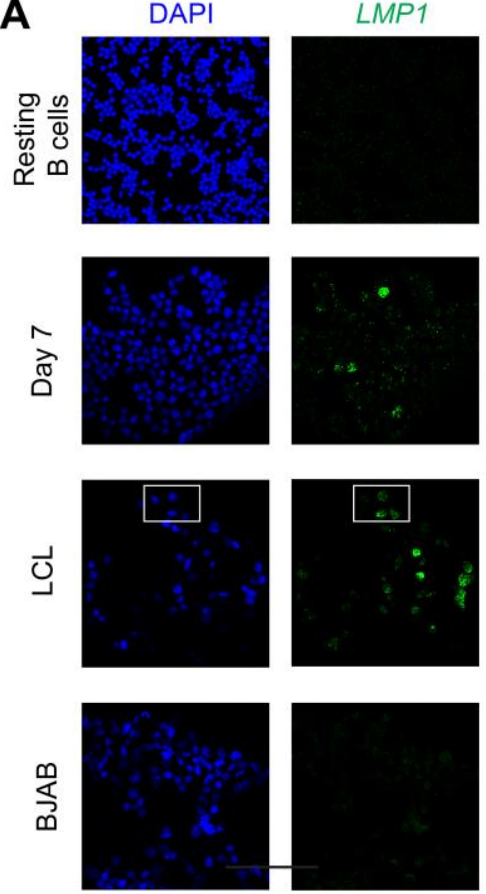

B

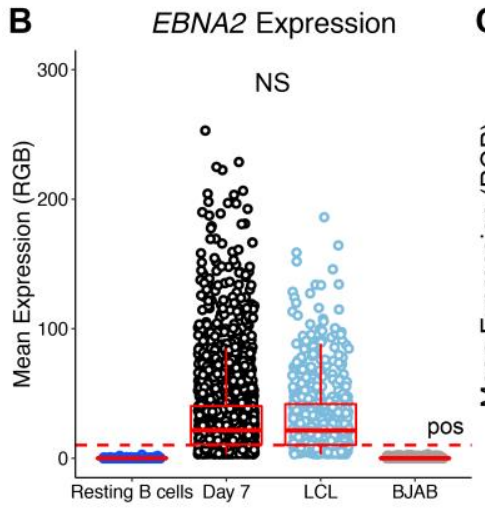

E

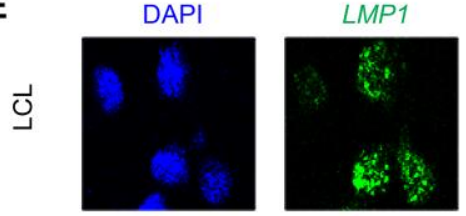

EBNA2
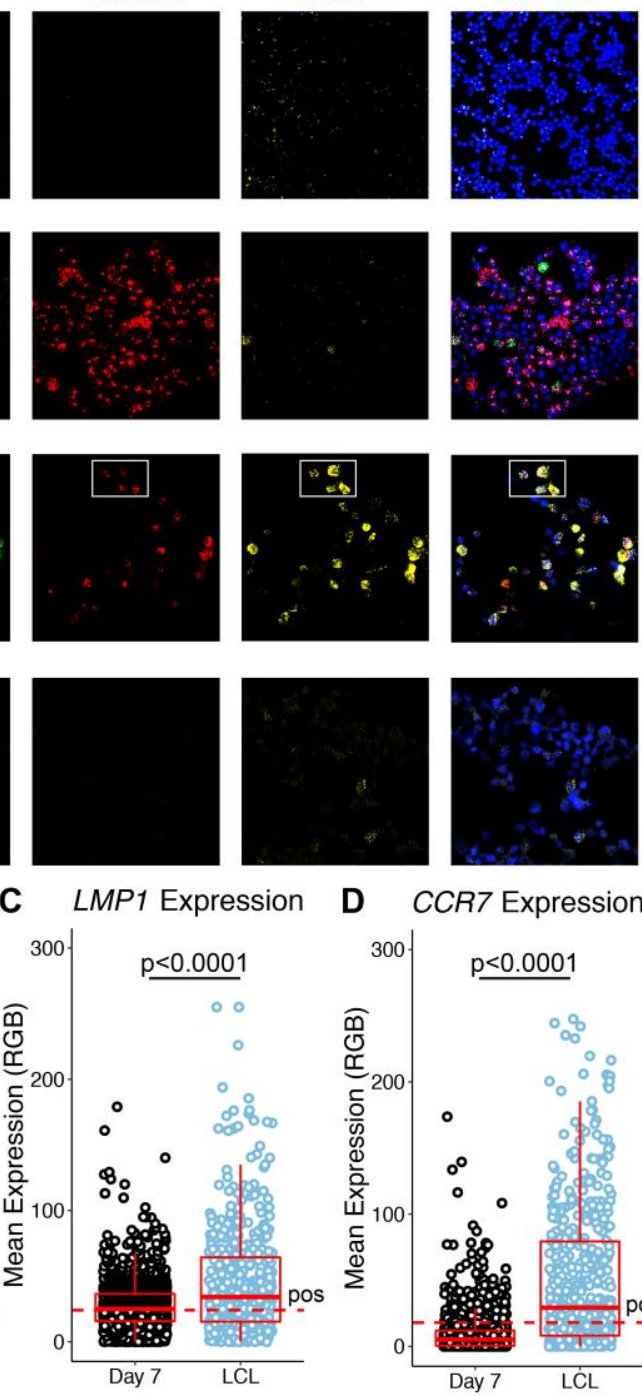

D CCR7 Expression

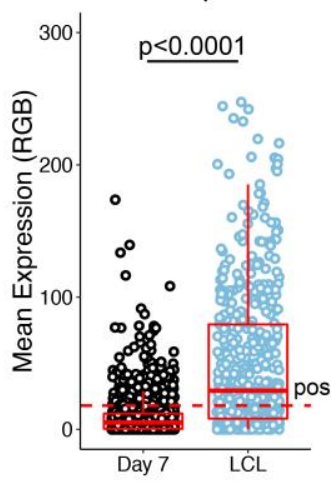

EBNA2
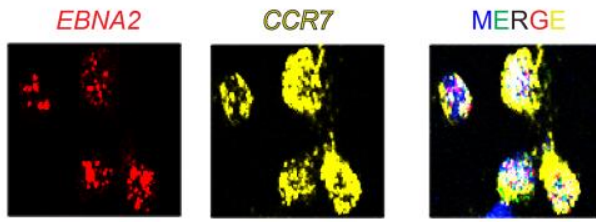

Figure 6: Multiplex RNA-FISH to distinguish EBV latency states A) Confocal immunofluorescence images from Resting B cells, day 7 dpi EBV+ latency $\mathrm{llb}$ proliferating B cells, LCLs and BJABs stained with LMP1, EBNA2 and CCR7 RNA FISH probes B) Quantification of EBNA2 expression. C) Quantification of LMP1 expression in EBNA2+ cells D) Quantification of CCR7 expression in EBNA2+ cells. E) Zoom in of boxed region in LCLs shown in A for EBNA2, LMP1 and CCR7 expression. For all quantifications, day 7 and LCLs are the average of 3 independent donors and seven fields of view. For resting $B$ cells this is representative of one blood donor and 7 fields of view. BJAB also represents the average of 7 fields of view. ${ }^{*} p<0.05,{ }^{* *} p<0.01,{ }^{* * *}$ $\mathrm{p}<0.001$ by one-tailed Mann-Whitney non-parametric t-test. All error bars denote SEM. 
504 Supplementary Data Legends:

505 Supplemental Table S1: List of genes downregulated from latency Ilb to ICAM-1 ${ }^{\text {lo }}$

506 LCL

507 Supplemental Table S2: List of genes upregulated from latency Ilb to ICAM-1 ${ }^{\text {lo }}$

$508 \quad$ LCL

509 Supplemental Table S3: List of latency IIb and latency III specific genes

510 


\section{References}

512 1. Miller CL, Burkhardt AL, Lee JH, Stealey B, Longnecker R, Bolen JB, Kieff E. 1995. 513 Integral membrane protein 2 of Epstein-Barr virus regulates reactivation from latency through dominant negative effects on protein-tyrosine kinases. Immunity 2:155-66.

2. Mosialos G, Birkenbach M, Yalamanchili R, VanArsdale T, Ware C, Kieff E. 1995. The Epstein-Barr virus transforming protein LMP1 engages signaling proteins for the tumor necrosis factor receptor family. Cell 80:389-99.

3. Kang MS, Kieff E. 2015. Epstein-Barr virus latent genes. Exp Mol Med 47:e131.

4. Nikitin PA, Yan CM, Forte E, Bocedi A, Tourigny JP, White RE, Allday MJ, Patel A, Dave SS, Kim W, Hu K, Guo J, Tainter D, Rusyn E, Luftig MA. 2010. An ATM/Chk2-mediated DNA damage-responsive signaling pathway suppresses Epstein-Barr virus transformation of primary human B cells. Cell Host Microbe 8:510-22.

5. Price AM, Tourigny JP, Forte E, Salinas RE, Dave SS, Luftig MA. 2012. Analysis of Epstein-Barr virus-regulated host gene expression changes through primary B-cell outgrowth reveals delayed kinetics of latent membrane protein 1-mediated NF-kappaB activation. J Virol 86:11096-106.

6. Zhao B, Zou J, Wang H, Johannsen E, Peng CW, Quackenbush J, Mar JC, Morton CC, Freedman ML, Blacklow SC, Aster JC, Bernstein BE, Kieff E. 2011. Epstein-Barr virus exploits intrinsic B-lymphocyte transcription programs to achieve immortal cell growth. Proc Natl Acad Sci U S A 108:14902-7.

7. Price AM, Dai J, Bazot Q, Patel L, Nikitin PA, Djavadian R, Winter PS, Salinas CA, Barry AP, Wood KC, Johannsen EC, Letai A, Allday MJ, Luftig MA. 2017. Epstein-Barr virus ensures $B$ cell survival by uniquely modulating apoptosis at early and late times after infection. Elife 6.

8. Price AM, Messinger JE, Luftig MA. 2018. c-Myc Represses Transcription of EpsteinBarr Virus Latent Membrane Protein 1 Early after Primary B Cell Infection. J Virol 92.

9. Choi IK, Wang Z, Ke Q, Hong M, Qian Y, Zhao X, Liu Y, Kim HJ, Ritz J, Cantor H, Rajewsky K, Wucherpfennig KW, Zhang B. 2018. Signaling by the Epstein-Barr virus LMP1 protein induces potent cytotoxic CD4(+) and CD8(+) T cell responses. Proc Natl Acad Sci U S A 115:E686-e695.

10. Brooks JM, Lee SP, Leese AM, Thomas WA, Rowe M, Rickinson AB. 2009. Cyclical expression of EBV latent membrane protein 1 in EBV-transformed B cells underpins heterogeneity of epitope presentation and CD8+ T cell recognition. J Immunol 182:191928.

11. Price AM, Luftig MA. 2014. Dynamic Epstein-Barr virus gene expression on the path to B-cell transformation. Adv Virus Res 88:279-313.

12. Cahir-McFarland ED, Davidson DM, Schauer SL, Duong J, Kieff E. 2000. NF-kappa B inhibition causes spontaneous apoptosis in Epstein-Barr virus-transformed lymphoblastoid cells. Proc Natl Acad Sci U S A 97:6055-60.

13. Lam N, Sandberg ML, Sugden B. 2004. High physiological levels of LMP1 result in phosphorylation of elF2 alpha in Epstein-Barr virus-infected cells. J Virol 78:1657-64.

14. Brink AA, Dukers DF, van den Brule AJ, Oudejans JJ, Middeldorp JM, Meijer CJ, Jiwa M. 1997. Presence of Epstein-Barr virus latency type III at the single cell level in posttransplantation lymphoproliferative disorders and AIDS related lymphomas. J Clin Pathol 50:911-8.

15. Oudejans JJ, Jiwa M, van den Brule AJ, Grasser FA, Horstman A, Vos W, Kluin PM, van der Valk P, Walboomers JM, Meijer CJ. 1995. Detection of heterogeneous Epstein-Barr virus gene expression patterns within individual post-transplantation lymphoproliferative disorders. Am J Pathol 147:923-33. 
560

561

562

563

564

565

566

567

568

569

570

571

572

573

574

575

576

577

578

579

580

581

582

583

584

585

586

587

588

589

590

591

592

593

594

595

596

597

598

599

600

601

602

603

604

605

606

607

608

609

610

16. McHugh D, Caduff N, Barros MHM, Ramer PC, Raykova A, Murer A, Landtwing V, Quast I, Styles CT, Spohn M, Fowotade A, Delecluse HJ, Papoudou-Bai A, Lee YM, Kim JM, Middeldorp J, Schulz TF, Cesarman E, Zbinden A, Capaul R, White RE, Allday MJ, Niedobitek G, Blackbourn DJ, Grundhoff A, Munz C. 2017. Persistent KSHV Infection Increases EBV-Associated Tumor Formation In Vivo via Enhanced EBV Lytic Gene Expression. Cell Host Microbe 22:61-73.e7.

17. Hafez AY, Messinger JE, McFadden K, Fenyofalvi G, Shepard CN, Lenzi GM, Kim B, Luftig MA. 2017. Limited nucleotide pools restrict Epstein-Barr virus-mediated B-cell immortalization. Oncogenesis 6:e349.

18. McFadden K, Hafez AY, Kishton R, Messinger JE, Nikitin PA, Rathmell JC, Luftig MA. 2016. Metabolic stress is a barrier to Epstein-Barr virus-mediated B-cell immortalization. Proc Natl Acad Sci U S A 113:E782-90.

19. Forte E, Luftig MA. 2009. MDM2-dependent inhibition of p53 is required for Epstein-Barr virus B-cell growth transformation and infected-cell survival. J Virol 83:2491-9.

20. Price AM, Luftig MA. 2015. To be or not llb: a multi-step process for Epstein-Barr virus latency establishment and consequences for B cell tumorigenesis. PLoS Pathog 11:e1004656.

21. Birkenbach M, Josefsen K, Yalamanchili R, Lenoir G, Kieff E. 1993. Epstein-Barr virusinduced genes: first lymphocyte-specific $G$ protein-coupled peptide receptors. J Virol 67:2209-20.

22. Wang F, Flanagan J, Su N, Wang LC, Bui S, Nielson A, Wu X, Vo HT, Ma XJ, Luo Y. 2012. RNAscope: a novel in situ RNA analysis platform for formalin-fixed, paraffinembedded tissues. J Mol Diagn 14:22-9.

23. Shaffer SM, Dunagin MC, Torborg SR, Torre EA, Emert B, Krepler C, Beqiri M, Sproesser K, Brafford PA, Xiao M, Eggan E, Anastopoulos IN, Vargas-Garcia CA, Singh A, Nathanson KL, Herlyn M, Raj A. 2017. Rare cell variability and drug-induced reprogramming as a mode of cancer drug resistance. Nature 546:431-435.

24. Laiho JE, Oikarinen M, Richardson SJ, Frisk G, Nyalwidhe J, Burch TC, Morris MA, Oikarinen S, Pugliese A, Dotta F, Campbell-Thompson M, Nadler J, Morgan NG, Hyöty H. 2016. Relative sensitivity of immunohistochemistry, multiple reaction monitoring mass spectrometry, in situ hybridization and PCR to detect Coxsackievirus B1 in A549 cells. J Clin Virol 77:21-8.

25. Nakajima N, Yoshizawa A, Kondo K, Rokutan-Kurata M, Hirata M, Furuhata A, Sumiyoshi S, Sonobe M, Menju T, Momose M, Fujimoto M, Date H, Haga H. 2017. Evaluating the effectiveness of RNA in-situ hybridization for detecting lung adenocarcinoma with anaplastic lymphoma kinase rearrangement. Histopathology 71:143-149.

26. Ma SD, Hegde S, Young KH, Sullivan R, Rajesh D, Zhou Y, Jankowska-Gan E, Burlingham WJ, Sun X, Gulley ML, Tang W, Gumperz JE, Kenney SC. 2011. A new model of Epstein-Barr virus infection reveals an important role for early lytic viral protein expression in the development of lymphomas. J Virol 85:165-77.

27. Rooney CM, Smith CA, Ng CY, Loftin S, Li C, Krance RA, Brenner MK, Heslop HE. 1995. Use of gene-modified virus-specific T lymphocytes to control Epstein-Barr-virusrelated lymphoproliferation. Lancet 345:9-13.

28. Heslop HE, Ng CY, Li C, Smith CA, Loftin SK, Krance RA, Brenner MK, Rooney CM. 1996. Long-term restoration of immunity against Epstein-Barr virus infection by adoptive transfer of gene-modified virus-specific T lymphocytes. Nat Med 2:551-5.

29. Rooney CM, Smith CA, Ng CY, Loftin SK, Sixbey JW, Gan Y, Srivastava DK, Bowman LC, Krance RA, Brenner MK, Heslop HE. 1998. Infusion of cytotoxic T cells for the prevention and treatment of Epstein-Barr virus-induced lymphoma in allogeneic transplant recipients. Blood 92:1549-55. 
611

612

613

614

615

616

617

618

619

620

621

622

623

624

625

626

627

628

629

630

631

632

633

634

635

636

637

638

639

640

641

642

643

644

645

646

647

648

649

650

651

652

30. Heslop HE, Slobod KS, Pule MA, Hale GA, Rousseau A, Smith CA, Bollard CM, Liu H, Wu MF, Rochester RJ, Amrolia PJ, Hurwitz JL, Brenner MK, Rooney CM. 2010. Longterm outcome of EBV-specific T-cell infusions to prevent or treat EBV-related lymphoproliferative disease in transplant recipients. Blood 115:925-35.

31. Barker JN, Doubrovina E, Sauter C, Jaroscak JJ, Perales MA, Doubrovin M, Prockop SE, Koehne G, O'Reilly RJ. 2010. Successful treatment of EBV-associated posttransplantation lymphoma after cord blood transplantation using third-party EBVspecific cytotoxic T lymphocytes. Blood 116:5045-9.

32. Doubrovina E, Oflaz-Sozmen B, Prockop SE, Kernan NA, Abramson S, TeruyaFeldstein J, Hedvat C, Chou JF, Heller G, Barker JN, Boulad F, Castro-Malaspina H, George D, Jakubowski A, Koehne G, Papadopoulos EB, Scaradavou A, Small TN, Khalaf R, Young JW, O'Reilly RJ. 2012. Adoptive immunotherapy with unselected or EBV-specific T cells for biopsy-proven EBV + lymphomas after allogeneic hematopoietic cell transplantation. Blood 119:2644-56.

33. Bollard CM, Rooney CM, Heslop HE. 2012. T-cell therapy in the treatment of posttransplant lymphoproliferative disease. Nat Rev Clin Oncol 9:510-9.

34. Bollard CM, Gottschalk S, Leen AM, Weiss H, Straathof KC, Carrum G, Khalil M, Wu MF, Huls MH, Chang CC, Gresik MV, Gee AP, Brenner MK, Rooney CM, Heslop HE. 2007. Complete responses of relapsed lymphoma following genetic modification of tumor-antigen presenting cells and T-lymphocyte transfer. Blood 110:2838-45.

35. Bollard CM, Gottschalk S, Torrano V, Diouf O, Ku S, Hazrat Y, Carrum G, Ramos C, Fayad L, Shpall EJ, Pro B, Liu H, Wu MF, Lee D, Sheehan AM, Zu Y, Gee AP, Brenner MK, Heslop HE, Rooney CM. 2014. Sustained complete responses in patients with lymphoma receiving autologous cytotoxic $\mathrm{T}$ lymphocytes targeting Epstein-Barr virus latent membrane proteins. J Clin Oncol 32:798-808.

36. McLaughlin LP, Rouce R, Gottschalk S, Torrano V, Carrum G, Wu MF, Hoq F, Grilley B, Marcogliese AM, Hanley PJ, Gee AP, Brenner MK, Rooney CM, Heslop HE, Bollard CM. 2018. EBV/LMP-specific T cells maintain remissions of T- and B-cell EBV lymphomas after allogeneic bone marrow transplantation. Blood 132:2351-2361.

37. Anonymous. Rituximab and LMP-Specific T-Cells in Treating Pediatric Solid Organ Recipients With EBV-Positive, CD20-Positive Post-Transplant Lymphoproliferative Disorder. https://ClinicalTrials.gov/show/NCT02900976.

38. Johannsen E, Luftig M, Chase MR, Weicksel S, Cahir-McFarland E, Illanes D, Sarracino D, Kieff E. 2004. Proteins of purified Epstein-Barr virus. Proc Natl Acad Sci U S A 101:16286-91.

39. Pertea M, Kim D, Pertea GM, Leek JT, Salzberg SL. 2016. Transcript-level expression analysis of RNA-seq experiments with HISAT, StringTie and Ballgown. Nat Protoc 11:1650-67.

40. Hinrichs AS, Zweig AS, Raney BJ, Haussler D, Karolchik D, Clawson H, Casper J, Speir ML, Haeussler M, Kent WJ. 2014. Navigating protected genomics data with UCSC Genome Browser in a Box. Bioinformatics 31:764-766. 